\title{
Oestrogen-induced genes in ductal carcinoma in situ: their comparison with invasive ductal carcinoma
}

\author{
Akiko Ebata, ${ }^{1,2}$,Takashi Suzuki ${ }^{3}$,Kiyoshi Takagi ${ }^{3}$, Yasuhiro Miki ${ }^{1}$, \\ Yoshiaki Onodera' ${ }^{1}$ Yasuhiro Nakamura ${ }^{1}$, Fumiyoshi Fujishima ${ }^{4}$,' \\ Kazuyuki Ishida ${ }^{4}$, Mika Watanabe ${ }^{4}$, Kentaro Tamaki ${ }^{1,2}$, Takanori Ishida ${ }^{2}$, \\ Noriaki Ohuchi ${ }^{2}$ and Hironobu Sasano ${ }^{1,4}$
}

Departments of ${ }^{1}$ Pathology, ${ }^{2}$ Surgical Oncology, and ${ }^{3}$ Pathology and Histotechnology, Tohoku University Graduate School of Medicine, 2-1 Seiryo-machi, Aobaku, Sendai, Japan

${ }^{4}$ Department of Pathology, Tohoku University Hospital, Sendai, Japan

(Correspondence should be addressed to H Sasano at Department of Pathology, Tohoku University Graduate School of Medicine; Email: hsasano@patholo2.med.tohoku.ac.jp)

\begin{abstract}
It is well known that oestrogens play important roles in both the pathogenesis and development of invasive ductal carcinoma (IDC) of human breast. However, molecular features of oestrogen actions have remained largely unclear in pure ductal carcinoma in situ (pDCIS), regarded as a precursor lesion of many IDCs. This is partly due to the fact that gene expression profiles of oestrogen-responsive genes have not been examined in pDCIS. Therefore, we first examined the profiles of oestrogen-induced genes in oestrogen receptor (ER)-positive pDCIS and DCIS (DCIS component (DCIS-C)) and IDC (IDC component (IDC-c)) components of IDC cases $(n=4$ respectively) by microarray analysis. Oestrogen-induced genes identified in this study were tentatively classified into three different groups in the hierarchical clustering analysis, and $33 \%$ of the genes were predominantly expressed in pDCIS rather than DCIS-C or IDC-c cases. Among these genes, the status of $M Y B$ (C-MYB), RBBP7 (RBAP46) and BIRC5 (survivin) expressions in carcinoma cells was significantly higher in ER-positive pDCIS $(n=53)$ than that in ER-positive DCIS-C $(n=27)$ or IDC-C $(n=27)$ by subsequent immunohistochemical analysis of the corresponding genes $(P<0.0001, P=0.03$ and $P=0.0003$ respectively). In particular, the status of C-MYB immunoreactivity was inversely $(P=0.006)$ correlated with Ki67 in the pDCIS cases. These results suggest that expression profiles of oestrogen-induced genes in pDCIS may be different from those in IDC; and C-MYB, RBAP46 and survivin may play important roles particularly among oestrogen-induced genes in ER-positive pDCIS.
\end{abstract}

Endocrine-Related Cancer (2012) 19 485-496

\section{Introduction}

Breast cancer is the most common malignant neoplasm in women worldwide. In particular, the incidence of ductal carcinoma in situ (DCIS) has been markedly increasing possibly due to advancements in population-based mammographic screening for detection (Li et al. 2005), and $\sim 20 \%$ of breast carcinoma cases actually present as pure DCIS (pDCIS) without invasive components at the time of diagnosis in many countries (Kepple et al. 2006, Tsikitis \& Chung 2006). This pDCIS is in general considered as a precursor lesion of invasive ductal carcinoma (IDC). It has been demonstrated that approximately half of untreated pDCIS progresses to IDC with marked variability in the latency of the progression (Cuzick 2003) and up to $80 \%$ of IDC were also reported to contain at least small foci of DCIS component (DCISc) distinct from the IDC component (IDC-c) if carefully evaluated (Ellis et al. 2003). Therefore, it has become very important to examine the biological features of pDCIS to identify the possible molecular mechanisms related to the acquisition of invasive 
properties and subsequently to improve clinical outcome of early breast cancer patients.

It is well known that oestrogens play important roles in the progression of breast carcinoma through an interaction with oestrogen receptor (ER). ER is expressed in approximately two-thirds of IDC, and endocrine therapy has been administered in these patients in order to suppress the intratumoural oestrogen actions. A great majority of pDCIS was also reported to express ER in their parenchymal cells (Wiechmann \& Kuerer 2008), and the results of National Surgical Adjuvant Breast Project (NSABP) B-24 trial did demonstrate that adjuvant tamoxifen therapy was clinically effective in ER-positive pDCIS and reduced the recurrence of noninvasive breast carcinomas by $27 \%$ (Cuzick 2003). Pathological and biological responses to preoperative tamoxifen therapy in ER-positive pDCIS patients has been also reported (Chen et al. 2009).

ER is well known to activate the transcription of various target genes in a ligand-dependent manner, and various oestrogenic functions are also characterised by expression profiles of these genes in oestrogen target cells. Various oestrogen-responsive genes have been also identified in IDC (Frasor et al. 2003), and an analysis of these genes can greatly contribute to the understanding of molecular functions of oestrogen actions, such as cell proliferation, anti-apoptosis, invasion, metastasis, recurrence and resistance to endocrine therapy, in IDC (Suzuki et al. 2012). However, expression profiles of oestrogen-responsive genes have not necessarily been examined in pDCIS to the best of our knowledge. Therefore, it has still remained unclear whether oestrogen actions and/or effectiveness of endocrine therapy in pDCIS could be the same as that in IDC.

Therefore, in this study, we first examined expression profiles of oestrogen-induced genes in carcinoma tissues of breast cancer patients and demonstrated different expression profiles of oestrogen-induced genes in ER-positive pDCIS from ER-positive DCIS-c or IDC-c following an isolation of the corresponding cells under light microscopy using laser-capture dissection. Subsequent microarray analysis indicated that $M Y B$ (C-MYB), RBBP7 (retinoblastoma suppressor $(\mathrm{Rb})$-associated protein 46 (RBAP46)) and BIRC5 (survivin) were predominantly expressed in pDCIS compared with DCIS-c and IDC-c among these oestrogen-induced genes. Therefore, we subsequently immunolocalised these gene products in ER-positive pDCIS tissues in order to further characterise their oestrogenic actions.

\section{Materials and methods}

\section{Patients and tissues}

Two sets of tissue specimens were used in this study. The first set is composed of eight specimens of ER-positive breast carcinoma (four pDCIS and four IDC cases) obtained from Japanese women (age: 51-77 years in pDCIS, and 49-75 years in IDC) who underwent surgical treatment from 2003 to 2008 in the Department of Surgery, Tohoku University Hospital, Sendai, Japan. One IDC patient was premenopausal, and the others were postmenopausal. All the IDC specimens used in this study contained both DCIS-c and IDC-c, and the patients did not receive chemotherapy, irradiation or hormonal therapy before the surgery. All the cases examined in this study were associated with nuclear grade 1 or 2, and their ER labelling index (LI) was ranged from 40 to $96 \%$ in pDCIS, 35 to $100 \%$ in DCIS-c and 42 to $100 \%$ in IDC-c respectively. These specimens were stored at $-80{ }^{\circ} \mathrm{C}$ for subsequent microarray analysis. The second set is composed of 80 specimens of ER-positive ductal carcinoma of human breast (53 pDCIS and 27 IDC cases) obtained from Japanese female patients who underwent surgical treatment from 1995 to 2008 in the Department of Surgery, Tohoku University Hospital, Sendai, Japan. These patients also did not receive chemotherapy, irradiation or hormonal therapy before the surgery. The median age of these patients was 61 years (range 39-80 years) for pDCIS and 55 (range 32-84 years) for IDC, and all the cases of IDC contained both DCIS-c and IDC-c in this study. All the specimens were fixed in $10 \%$ formalin and embedded in paraffin wax.

The entire resected surgical specimen was sectioned into slices with 3-5 mm thickness, and all the slices were histologically evaluated by surgical pathologists. In this study, pDCIS was defined when DCIS-c was detected but no foci of stromal invasion in carcinoma were detected in all the slides of the cases evaluated. In the first set, thinner section stained with haematoxylin and eosin was prepared from the frozen specimen, and histological features of these lesions were confirmed.

Research protocols for this study were approved by the Ethics Committee at Tohoku University Graduate School of Medicine (accession no. 2009-107).

\section{Laser-capture microdissection/microarray analysis}

Gene expression profiles of breast carcinoma cells in the first set of the specimens (four pDCIS, four DCIS-c and four IDC-c samples) were examined using microarray analysis. Laser-capture microdissection 
(LCM) was conducted using the MMI Cellcut (Molecular Machines and Industries, Flughofstrase, Glattbrugg, Switzerland). Briefly, breast carcinomas were embedded in Tissue-Tek optimal cutting temperature compound (Sakura Finetechnical Co., Tokyo, Japan) and sectioned at a thickness of $10 \mu \mathrm{m}$. Breast carcinoma cells were dissected under the light microscopy and laser transferred from these frozen sections. The total RNA ( $\sim 200 \mathrm{ng}$ ) was subsequently extracted from these cell fractions isolated by LCM using the RNeasy Micro Kit (Qiagen). In IDC cases, carcinoma cells were separately collected in DCIS-c and IDC-c. Whole Human Genome Oligo Microarray (G4112F (ID: 012391)), Agilent Technologies (Waldbronn, Germany), containing 41000 unique probes, was used in this study, and sample preparation and processing were performed according to the manufacturer's protocol. In this study, we focused on the expression of 51 genes identified to be oestrogeninduced ones in MCF7 breast carcinoma cells by Frasor et al. (2003) (two genes corresponding $P P P 2 R 1 B$ were included in this analysis). Hierarchical clustering analysis was performed using the Cluster and TreeView programs (the software copyright Stanford University 1998-1999, http://rana.stanford. edu) to generate tree structures based on the degree of similarity, as well as matrices comparing the levels of expression of individual genes in each specimens.

\section{Immunohistochemistry}

Immunohistochemical analysis was performed in the second set (53 pDCIS and 27 IDC cases) described above. Monoclonal antibodies for ER (6F11), progesterone receptor (PR; 1A6) and Ki67 (MIB1) were purchased from NovoCastra (Newcastle upon Tyne, UK), Chemicon (Temecula, CA, USA) and DAKO (Carpinteria, CA, USA) respectively. Rabbit polyclonal antibodies for human epidermal growth factor receptor-2 (HER2; A0485) were obtained from DAKO. In addition, rabbit polyclonal antibodies for C-MYB (EPR718(2)), RBAP46 (EPR5082) and survivin (NB500-201) were purchased from Epitomics (Burlingame, CA, USA) and Novus Biologicals (Littleton, CO, USA) respectively.

A Histofine Kit (Nichirei Biosciences, Tokyo, Japan) that employs the streptavidin-biotin amplification method was used in this study. Antigen retrieval was performed by heating the slides in an autoclave at $120^{\circ} \mathrm{C}$ for $5 \mathrm{~min}$ in antigen retrieval solution $(\mathrm{pH} 9.0$; Nichirei Biosciences) for C-MYB immunostaining or citric acid buffer ( $2 \mathrm{mM}$ citric acid and $9 \mathrm{mM}$ trisodium citrate dehydrate ( $\mathrm{pH}$ 6.0)) for immunostaining of other antibodies. Dilutions of primary antibodies used in this study were as follows: ER, 1/50; PR, 1/50; HER2, 1/100; Ki67, 1/100; C-MYB, 1/50; RBAP46, 1/1000 and survivin, $1 / 1000$. The antigen-antibody complex was subsequently visualised with 3,3'-diaminobenzidine (DAB) solution (1 mM DAB, $50 \mathrm{mM}$ Tris-HCl buffer ( $\mathrm{pH}$ 7.6) and $0.006 \% \mathrm{H}_{2} \mathrm{O}_{2}$ ) and counterstained with haematoxylin. As a positive control, human IDC tissue was used for C-MYB (McHale et al. 2008) and survivin (Barnes et al. 2006) immunostaining, and a cellblock of MCF7 breast carcinoma cells was used for RBAP46 (Creekmore et al. 2008). Normal rabbit IgG was used instead of the primary antibody, as a negative control in this study.

\section{Immunohistochemical evaluation}

Immunoreactivity of ER, PR and Ki67 was detected in the nucleus, and their immunoreactivity was evaluated in counting more than 1000 carcinoma cells for each case. The percentage of immunoreactivity, i.e. LI, was subsequently determined. Cases with ER LI of more than $1 \%$ were considered ER-positive breast carcinoma in this study (Hammond et al. 2010). HER2 immunoreactivity was evaluated according to the grading system proposed in HercepTest (DAKO), and strongly circumscribed membrane-immunoreactivity of HER 2 present in more than $30 \%$ carcinoma cells were considered positive (Wolff et al. 2007). Both C-MYB and RBAP46 immunoreactivities were detected in the nuclei of carcinoma cells and were evaluated by employing the H-scoring system (McCarty et al. 1985). Briefly, C-MYB- and RBAP46-positive carcinoma cells were classified into three groups according to immunointensity (i.e. strongly, moderately or weakly positive cells), and $\mathrm{H}$ scores were subsequently generated by adding together $3 \times \%$ of strongly positive cells, $2 \times \%$ of moderately positive cells, $1 \times \%$ weakly positive cells, and $0 \times \%$ of negative cells (range $0-300$ ). Survivin immunoreactivity was detected in the cytoplasm of carcinoma cells and was semi-quantitatively evaluated by modified H-scoring system (Mehta et al. 2012), in which the percentage of cytoplasmic immunoreactivity was categorised as 0 (no expression), 10 (up to 10\%), $20(10-20 \%)$ until 100 (90-100\%), and giving a possible range of $0-300$.

\section{Statistical analysis}

An association of various clinicopathological factors among three carcinoma components (pDCIS, DCIS-c and IDC-c) was evaluated using a Kruskal-Wallis test or a cross-table with the $\chi^{2}$ test. An association between C-MYB, RBAP46 and survivin immunoreactivity and 
clinicopathological factors was evaluated by a crosstable using the $\chi^{2}$ test. An association of clinicopathological factors between two components of IDC cases was evaluated using a Wilcoxon signed-ranks test. The statistical analyses were performed using the JMP Pro version 9.02 (SAS Institute, Inc., Cary, NC, USA), and $P$ values of $<0.05$ were considered significant in this study.

\section{Results}

\section{Expression profiles of oestrogen-induced genes in pDCIS compared with those of DCIS-c and IDC-C}

We first surveyed expression profiles of oestrogeninduced genes in isolated carcinoma cells of pDCIS using microarray analysis which was focused on oestrogen-induced genes reported by Frasor et al. (2003), in order to examine the characteristics of oestrogenic actions in pDCIS. Fifty-one oestrogeninduced genes examined were tentatively classified into three groups (i.e. Groups A, B and C) depending on the hierarchical clustering analysis (Fig. 1). In addition, isolated and examined pDCIS carcinoma cells were clustered among the cases examined. Results demonstrated that the genes in Group C were predominantly expressed in pDCIS rather than in DCIS-c or IDC-c, and the genes in Group A were predominantly expressed in DCIS-c and/or IDC-c. Genes classified into Group B were expressed regardless of the carcinoma types. No significant clustering of samples was detected in association with nuclear grade, menopausal status and ER LI of the cases examined in this study.

As shown in Table 1, no significant differences of characteristics were detected between Groups A and C in this study.

\section{Clinicopathological features of pDCIS, DCIS-C and IDC-C}

We then evaluated an association of various clinicopathological parameters among pDCIS ( $n=53$ ), DCIS$\mathrm{c}(n=27)$ and IDC-c $(n=27)$, which were examined in this study. Nuclear grade $(P=0.68)$, ER LI $(P=0.94)$, PR LI $(P=0.87)$ and HER2 status $(P=0.33)$ were not significantly different among these three groups, but Ki67 LI was significantly $(P<0.0001)$ lower in pDCIS than that in DCIS-c and IDC-c (Table 2). No significant differences of patients' age $(P=0.43)$ and menopausal status $(P=0.34)$ were detected between pDCIS and IDC patients in this study. HER2 positive status in our study (45\% in pDCIS, $33 \%$ in DCIS-c and $30 \%$ in IDC-c) was consistent with that of a previous report (Park et al. 2006).

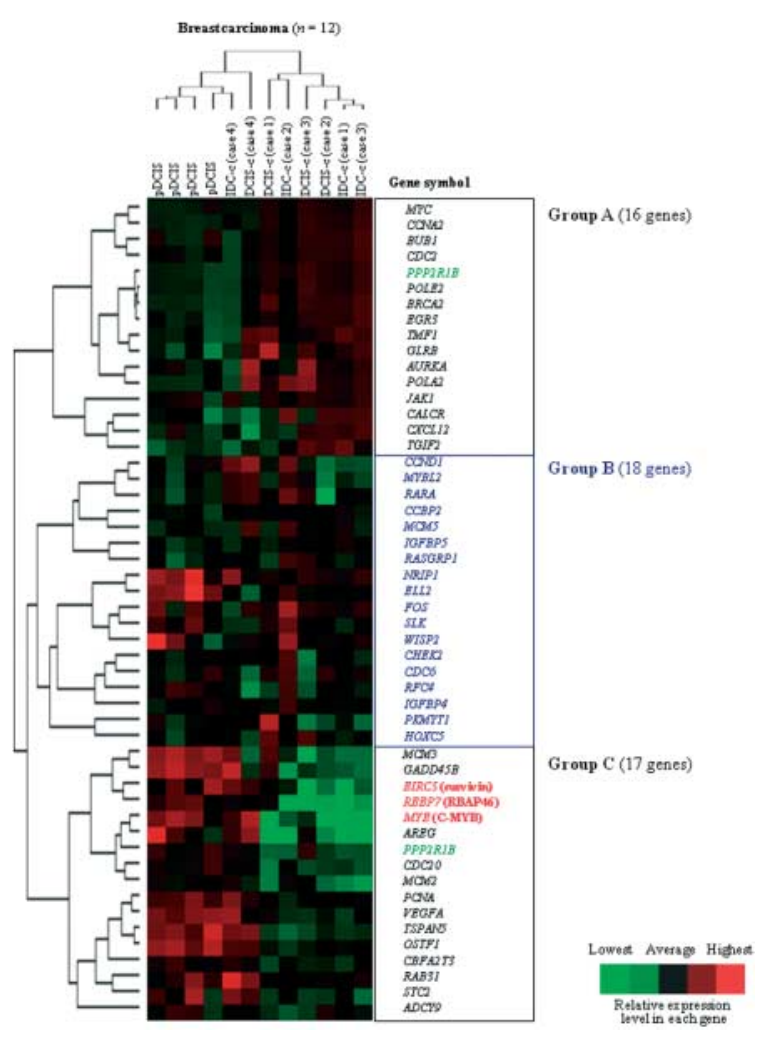

Figure 1 Hierarchical clustering analysis of mRNA expression levels focused on oestrogen-induced genes identified by Frasor et al. (2003). Colour of blocks represents relative mRNA expression level of each gene compared with the average in 12 breast carcinoma samples (four pDCIS, four DCIS-c and four IDC-c). Gene symbols in each gene were listed. Geneperformed immunohistochemistry was noted in red. Two genes corresponding PPP2R1B were coloured green.

\section{Immunolocalisation of C-MYB, RBAP46 and survivin in pDCIS}

Results of the microarray analysis demonstrate different expression profiles of oestrogen-induced genes in pDCIS compared with those in DCIS-c and IDC-c. We then performed immunohistochemistry for three representative oestrogen-induced genes (C-MYB $(M Y B)$, RBAP46 (RBBP7) and survivin (BIRC5)) in the breast carcinoma tissues in Group $C$ towards further confirmation of the findings.

As demonstrated in Fig. 2A, C-MYB was immunolocalised in the nuclei of carcinoma cells, and its $\mathrm{H}$-score was significantly $(P<0.0001)$ higher in pDCIS than that in DCIS-c or IDC-c (Fig. 2B). RBAP46 immunoreactivity was also detected in the nuclei of carcinoma cells (Fig. 2C), and its immunoreactivity was significantly $(P=0.03)$ higher in pDCIS (Fig. 2D). 
Table 1 Comparison of characteristics of genes between Groups A and C

\begin{tabular}{|c|c|c|c|}
\hline \multirow[b]{2}{*}{ Characteristic of genes } & \multicolumn{2}{|c|}{ Number of genes } & \multirow[b]{2}{*}{$P$ value } \\
\hline & $\begin{array}{c}\text { Group A } \\
(n=15)\end{array}$ & $\begin{array}{c}\text { Group C } \\
(n=16)\end{array}$ & \\
\hline \multicolumn{4}{|c|}{ First time of significant upregulation by oestrogen } \\
\hline $4 \mathrm{~h}$ & $7(47 \%)$ & $11(69 \%)$ & 0.51 \\
\hline $8 \mathrm{~h}$ & $1(7 \%)$ & $0(0 \%)$ & \\
\hline $24 \mathrm{~h}$ & $5(33 \%)$ & $4(25 \%)$ & \\
\hline $48 \mathrm{~h}$ & $2(13 \%)$ & $1(6 \%)$ & \\
\hline \multicolumn{4}{|l|}{ Major biological function } \\
\hline Cell cycle and apoptosis & $6(40 \%)$ & $5(31 \%)$ & \\
\hline $\begin{array}{l}\text { Growth factors, cytokines } \\
\text { and hormones }\end{array}$ & $1(7 \%)$ & $3(19 \%)$ & \\
\hline $\begin{array}{l}\text { Receptors and signal } \\
\text { transduction proteins }\end{array}$ & $2(13 \%)$ & $5(31 \%)$ & 0.34 \\
\hline $\begin{array}{l}\text { Transcription factors } \\
\text { and transcriptional } \\
\text { coregulators }\end{array}$ & $6(40 \%)$ & $3(19 \%)$ & \\
\hline
\end{tabular}

Data of characteristics of genes were taken from a report by Frasor et al. (2003). Data are presented as the number of cases and percentage. Two genes corresponding PPP2R1B were excluded in this table, because these were classified into both Groups A and C.

Survivin was immunolocalised in the cytoplasm of carcinoma cells, and some nuclei of the carcinoma cells were also immunohistochemically positive for survivin (Fig. 2E). Relative survivin immunoreactivity was significantly $(P=0.0003)$ higher in pDCIS than that in DCIS-c or IDC-c (Fig. 2F).

As shown in Table 3, when we divided the cases into two groups according to several important pathological factors, such as nuclear grade, HER2 status and ER LI, C-MYB immunoreactivity was significantly higher in pDCIS than that in DCIS-c or IDC-c regardless of the status. Similar tendency was also detected in RBAP46 and survivin immunoreactivities; but $P$ values did not reach significant levels in some groups.
As two genes corresponding PPP $2 R 1 B$ were classified into different groups (i.e. Groups A and C) in the microarray analysis (Fig. 1), we performed immunohistochemistry of PPP2R1B (also known as a protein phosphatase 2 , regulatory subunit $\mathrm{A}, \beta$ (PP2A$A \beta)$ ) in these cases. PPP2R1B immunoreactivity was detected in the breast carcinoma cells (Supplementary Figure S1A, see section on supplementary data given at the end of this article), but its immunointensity was generally weak and was not significantly different among the pDCIS, DCIS-c and IDC-c groups examined in this study (Supplementary Figure S1B, see section on supplementary data given at the end of this article).

\section{Association between C-MYB, RBAP46 and survivin immunoreactivity and various clinicopathological parameters in pDCIS}

Results of both microarray and immunohistochemical analyses described earlier indicated that C-MYB, RBAP46 and survivin were abundantly expressed in pDCIS. As demonstrated in Table 4, when 53 pDCIS cases examined were tentatively classified into two different groups according to the median value of C-MYB H-score, the status of C-MYB immunoreactivity was inversely $(P=0.006)$ associated with Ki67 LI in pDCIS cases. No other significant association was detected between C-MYB immunoreactivity and other clinicopathological parameters of the patients examined, such as patients' age, menopausal status, nuclear grade, comedo necrosis, ER LI, PR LI and HER2 status. The status of RBAP46 immunoreactivity was not significantly associated with any clinicopathological parameters examined (Table 5), while the status of survivin immunoreactivity was positively associated with patients' age $(P=0.002$; Table 6$)$. Association between PPP2R1B immunoreactivity and clinicopathological parameters in pDCIS cases is summarised

Table 2 Association of various clinicopathological parameters among pDCIS, DCIS-c and IDC-C

\begin{tabular}{|c|c|c|c|c|}
\hline Parameter & pDCIS $(n=53)$ & DCIS-c $(n=27)$ & IDC-c $(n=27)$ & $P$ value \\
\hline \multicolumn{5}{|l|}{ Nuclear grade ${ }^{a}$} \\
\hline Grades $1+2$ & 44 (83\%) & 24 (89\%) & 24 (89\%) & 0.68 \\
\hline Grade 3 & $9(17 \%)$ & $3(11 \%)$ & $3(11 \%)$ & \\
\hline ER LI (\%) & $81(12-100)$ & $80(15-100)$ & $80(8-100)$ & 0.94 \\
\hline PR LI (\%) & $40(0-100)$ & $40(0-100)$ & $40(0-100)$ & 0.87 \\
\hline \multicolumn{5}{|l|}{ HER2 status ${ }^{a}$} \\
\hline Negative & $29(55 \%)$ & $18(67 \%)$ & $19(70 \%)$ & 0.33 \\
\hline Positive & $24(45 \%)$ & 9 (33\%) & $8(30 \%)$ & $<0.0001$ \\
\hline Ki67 LI (\%) & $4(1-12)$ & $8(1-23)$ & $12(1-32)$ & \\
\hline
\end{tabular}

$P$ value $<0.05$ was considered significant and is in boldface.

${ }^{a}$ Data are presented as the number of cases and percentage. All other values represent the median (min-max). 


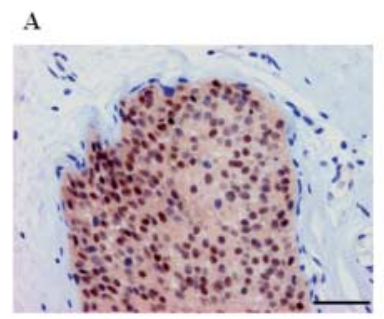

B
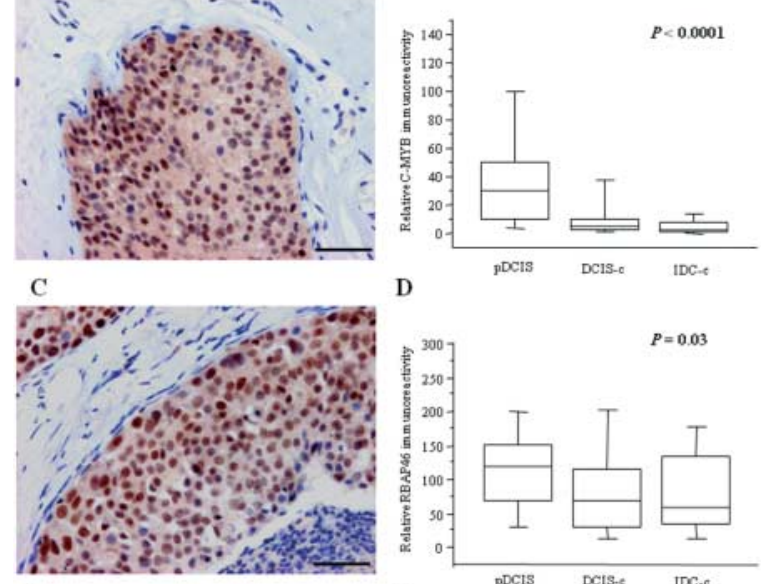

E
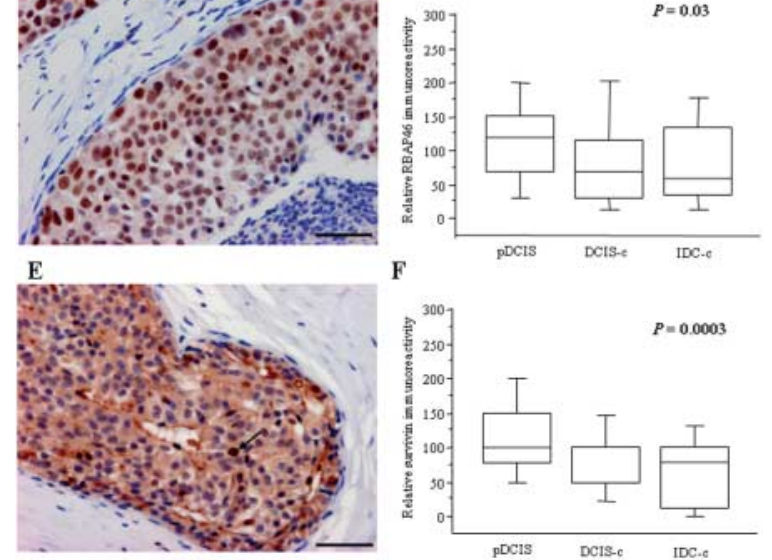

F

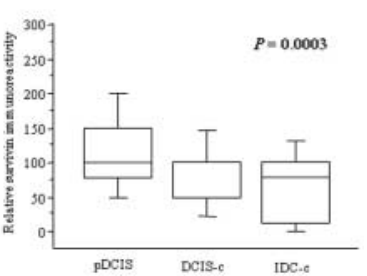

Figure 2 Immunohistochemistry for C-MYB (A and B), RBAP46 $(C$ and $D)$ and survivin $(E$ and $F)$ in the breast cancer cases. Immunoreactivity of C-MYB (A) and RBAP46 (C) was detected in nuclei of carcinoma cells in pDCIS. Survivin was immunolocalised in the cytoplasm of carcinoma cells in pDCIS and was also positive in some nuclei of the carcinoma cells (an arrow; E). $\mathrm{Bar}=50 \mu \mathrm{m}$ respectively. Relative immunoreactivity of C-MYB, RBAP46 and survivin in pDCIS, DCIS-C and IDC-c was summarised in $B, D$ and $F$ respectively. Data are represented as box and whisker plots. Briefly, the median value is represented by a horizontal line in each box, and the 75th (upper margin) and 25th (lower margin) percentiles of the values are demonstrated. The upper and lower bars indicate the maximum and minimum values respectively. In $\mathrm{F}$, the median value of relative survivin immunoreactivity in DCIS-c was 100 . Statistical analysis was carried out using the Kruskal-Wallis test. $P$ values $<0.05$ were considered significant and were indicated in bold letter.

in Supplementary Table S1, see section on supplementary data given at the end of this article.

\section{Association between clinicopathological parameters and three oestrogen-induced proteins in DCIS-c and IDC-C}

As summarised in Table 7, Ki67 LI was significantly lower $(P=0.04)$ in DCIS-c than that in IDC-c, but no significant differences between clinicopathological parameters of the patients and the status of immunoreactivity of C-MYB, RBAP46 and survivin were detected between DCIS-c and IDC-c of 27 IDC patients in this study.

\section{Discussion}

pDCIS is generally considered as a precursor lesion of IDC. Two different models have been proposed to explain the possible mechanisms of transition from pDCIS to IDC, i.e. theories of linear progression or parallel disease (Wiechmann \& Kuerer 2008). In the former model, low-grade pDCIS lesions are considered to progress to high-grade pDCIS lesions and then to become IDC (Carter et al. 1988, Bodian et al. 1993, Lakhani et al. 1999). In the latter model of hypothesis, low-grade pDCIS lesions progress to low-grade IDC and high-grade pDCIS lesions to high-grade IDC (Sontag \& Axelrod 2005, Wiechmann \& Kuerer 2008). Accumulating data including chromosomal-alteration studies support the parallel disease theory (Hwang et al. 2004, Irvine \& Fentiman 2007), and the great majority of molecular alterations detected in breast carcinoma, including ESR 1 which codes for ER, can be clearly detected already in pDCIS, whether high or low grades (Nofech-Mozes et al. 2005, Burkhardt et al. 2010). In this study of ER-positive breast carcinoma, both ER and PR LIs in pDCIS were similar to those in IDC-c or DCIS-c, which is considered to be compatible with parallel disease theory of development. Shibuya et al. (2008) also previously demonstrated that various oestrogen-producing enzymes were abundantly expressed in pDCIS, and intratumoural oestrogen concentration was similar between pDCIS and IDC (Shibuya et al. 2008). Therefore, oestrogens are considered to play pivotal roles in pDCIS as well as in IDC.

Results of our present study also demonstrated that Ki67 LI was significantly lower in ER-positive pDCIS than that in ER-positive IDC. Antibody Ki67 recognises cells located in all the phases of cell cycle except for $\mathrm{G}_{0}$ (resting) phase (Gerdes et al. 1983), and Ki67 LI is closely correlated with the cell proliferation activity of the tissues (van Diest et al. 2004). Ki67 was also reported as a prognostic factor in pDCIS (van Diest et al. 2004) as well as in IDC (de Azambuja et al. 2007), and increased Ki67 was associated with negative ER status of breast carcinoma (Burkhardt et al. 2010). All these findings suggest that oestrogen actions are more associated with cell proliferation of breast carcinoma in IDC than in pDCIS.

This is the first study to demonstrate expression profiles of oestrogen-induced genes in pDCIS compared with IDC. Results of our present microarray analysis did reveal that one-third of oestrogen-induced genes were predominantly expressed in pDCIS, while the other one-third of the genes mainly in IDC and the rest in both categories with equivalent frequency. 
Table 3 Statistical associations of C-MYB, RBAP46 and survivin immunoreactivity among pDCIS, DCIS-c and IDC-c cases according to several pathological parameters

\begin{tabular}{lccc}
\hline Parameter & C-MYB immunoreactivity & RBAP46 immunoreactivity & Survivin immunoreactivity \\
\hline Nuclear grade & & & $\mathbf{0 . 0 4}$ \\
Grades 1+2 & $\mathbf{0 . 0 0 0 1}$ & 0.5 & $\mathbf{0 . 0 0 1}$ \\
Grade 3 & $\mathbf{0 . 0 0 8}$ & $\mathbf{0 . 0 2}$ & 0.3 \\
HER2 status & & $\mathbf{0 . 0 0 0 1}$ & $\mathbf{0 . 0 1}$ \\
Negative & $\mathbf{0 . 0 1}$ & 0.73 & $\mathbf{0 . 0 2}$ \\
Positive & $\mathbf{0 . 0 0 0 3}$ & 0.06 & $\mathbf{0 . 0 1}$ \\
ER LI (\%) & $\mathbf{0 . 0 0 0 2}$ & 0.20 & $\mathbf{0 . 0 0 8}$ \\
8-79 & & \\
80-100 & & & \\
\hline
\end{tabular}

Data are presented as $P$ values. $P$ values $<0.05$ were considered significant and are in boldface.

These findings suggest that oestrogenic actions in pDCIS were different from those in IDC, even if the carcinoma cells expressed ER and intratumoural oestrogen was present at a significant level in both of these lesions. Among the genes predominantly expressed in IDC (Group A in Fig. 1), EGR3 (early growth-responsive gene 3) was reported to play a pivotal role in the process of oestrogen-mediated invasion in breast cancer, and its expression was associated with adverse clinical outcome of the patients with ER-positive IDC (Suzuki et al. 2007). In addition, the kinetochore-bound protein kinase $B U B 1$ (budding uninhibited by benzimidazoles 1) is also considered to play possible role in the process of breast tumourigenesis (Klebig et al. 2009), and its mRNA expression was also reported to be positively associated with clinical recurrence in ER-positive IDC patients (Suzuki et al. 2012). MYC (C-MYC) was also reported to be associated with poor prognosis or adverse clinical outcome of ER-positive breast cancer patients (Chen \& Olopade 2008). Robanus-Maandag et al. (2003) reported that MYC amplification may drive transition from pDCIS to IDC in human breast (Robanus-Maandag et al. 2003), although some conflicting data were reported in the literature (Burkhardt et al. 2010). These findings suggest that oestrogen-mediated transactivation is considered to vary among the target genes, and the genes promoting aggressive biological or clinical behaviour of breast carcinoma cells may be more efficiently induced by oestrogen in IDC. However, immunoreactivity of C-MYB, RBAP46 and survivin was not associated with ER LI in pDCIS cases in this study, and previous studies have demonstrated that the expression of these molecules was regulated by several factors (for instances, miroRNA-150 downregulated C-MYB in liver cancer stem cells (Zhang et al. 2012), RBAP46 functioned as a downstream target gene of WT1 (Guan et al. 1998), and genetic variants of the survivin promotor were associated with survivin expression $(\mathrm{Xu}$ et al. 2004)). Therefore, factors other than oestrogen may also be involved in the different expression profiles of oestrogen-induced genes in pDCIS from IDC. Our experiments serve as a starting point for clarifying the molecular features of oestrogen actions in pDCIS, and further examination is required.

We first identified C-MYB, RBAP46 and survivin as oestrogen-induced proteins predominantly expressed in pDCIS compared with IDC in this study. Among these three genes identified by gene profilings, a nuclear transcription factor C-MYB regulates differentiation and proliferation in various types of cells $(\mathrm{Oh}$ \& Reddy 1999), and expression of $C-M Y B$ mRNA was

Table 4 Association between C-MYB immunoreactivity and clinicopathological parameters in pDCIS

\begin{tabular}{|c|c|c|c|}
\hline \multirow[b]{2}{*}{ Parameter } & \multicolumn{2}{|c|}{ C-MYB immunoreactivity } & \multirow[b]{2}{*}{$P$ value } \\
\hline & High $(n=26)$ & Low $(n=27)$ & \\
\hline \multicolumn{3}{|l|}{ Menopausal status $^{a}$} & 0.91 \\
\hline Premenopausal & $7(30 \%)$ & $3(56 \%)$ & 0.14 \\
\hline \multicolumn{3}{|l|}{ Nuclear grade $^{a}$} & \\
\hline Grades $1+2$ & $20(77 \%)$ & $24(89 \%)$ & 0.25 \\
\hline Grade 3 & $6(23 \%)$ & $3(11 \%)$ & \\
\hline \multicolumn{4}{|l|}{ Comedo necrosis $^{a}$} \\
\hline Absent & $11(42 \%)$ & 7 (26\%) & 0.21 \\
\hline Present & $15(58 \%)$ & $20(74 \%)$ & \\
\hline ER LI (\%) & $84(13-100)$ & $80(12-100)$ & 0.77 \\
\hline PR LI (\%) & $40(6-93)$ & $46(0-100)$ & 0.72 \\
\hline \multicolumn{4}{|l|}{ HER2 status ${ }^{a}$} \\
\hline Negative & $14(54 \%)$ & $15(56 \%)$ & 0.90 \\
\hline Positive & $12(46 \%)$ & $12(44 \%)$ & \\
\hline Ki67 LI (\%) & $3(1-10)$ & $6(2-12)$ & 0.006 \\
\hline
\end{tabular}

Fifty-three pDCIS cases were classified into two (i.e. high and low) groups according to the median value of C-MYB immunoreactivity. $P$ value $<0.05$ was considered significant and is in boldface.

${ }^{a}$ Data are presented as the number of cases and percentage. All other values represent the median (min-max). 
Table 5 Association between RBAP46 immunoreactivity and clinicopathological parameters in pDCIS

\begin{tabular}{|c|c|c|c|}
\hline \multirow[b]{2}{*}{ Parameter } & \multicolumn{2}{|c|}{ RBAP46 immunoreactivity } & \multirow[b]{2}{*}{$P$ value } \\
\hline & High $(n=28)$ & Low $(n=25)$ & \\
\hline Patients' age & $65(39-80)$ & $54(49-77)$ & 0.06 \\
\hline \multicolumn{4}{|l|}{ Menopausal status $^{a}$} \\
\hline Premenopausal & $4(14 \%)$ & $6(24 \%)$ & 0.81 \\
\hline Postmenopausal & $24(86 \%)$ & $19(76 \%)$ & \\
\hline \multicolumn{4}{|l|}{ Nuclear grade ${ }^{a}$} \\
\hline Grades $1+2$ & $21(75 \%)$ & $23(92 \%)$ & 0.99 \\
\hline Grade 3 & $7(25 \%)$ & $2(8 \%)$ & \\
\hline \multicolumn{4}{|l|}{ Comedo necrosis $^{a}$} \\
\hline Absent & $9(32 \%)$ & $9(36 \%)$ & 0.77 \\
\hline Present & $19(68 \%)$ & $16(64 \%)$ & \\
\hline ER LI (\%) & $88(12-100)$ & $80(13-100)$ & 0.60 \\
\hline PR LI (\%) & $44(6-100)$ & $40(0-100)$ & 0.19 \\
\hline \multicolumn{4}{|l|}{ HER2 status ${ }^{a}$} \\
\hline Negative & $16(57 \%)$ & $13(52 \%)$ & 0.71 \\
\hline Positive & $12(43 \%)$ & $12(48 \%)$ & \\
\hline Ki67 LI (\%) & $4(1-12)$ & $4(2-10)$ & 0.31 \\
\hline
\end{tabular}

Fifty-three pDCIS cases were classified into two (i.e. high and low) groups according to the median value of RBAP46 immunoreactivity.

${ }^{a}$ Data are presented as the number of cases and percentage. All other values represent the median (min-max).

rapidly stimulated by oestrogen administration in the MCF7 breast carcinoma cells (Frasor et al. 2003). C-MYB protein was detected in ER-positive IDC and was associated with a good prognosis in the patients (Guerin et al. 1990, Drabsch et al. 2007, Deisenroth et al. 2010, Thorner et al. 2010). Immunohistochemistry for C-MYB in pDCIS has been reported only by McHale et al. (2008) to the best of our knowledge, in which C-MYB immunoreactivity in the breast carcinoma containing both pDCIS and IDC was significantly higher than that in normal/hyperplastic epithelium. Results of our present study first demonstrated that C-MYB immunoreactivity was significantly higher in pDCIS than in IDC and was inversely associated with Ki67 LI in pDCIS. Very recently, Thorner et al. (2010) reported that stable RNAi knock-down of endogenous $C-M Y B$ in the MCF7 cells increased tumourigenesis, both in vitro and in vivo, suggesting a tumour suppressor function in luminal breast cancer subtypes (Thorner et al. 2010). Results of our present study are consistent with these previously reported studies, and decreased induction of C-MYB expression by oestrogen may result in the possible acceleration of oestrogen-mediated cell proliferation of breast carcinoma in IDC.

RBAP46, a nuclear protein, was originally identified as histone-binding proteins and its components of protein complexes have been demonstrated to be involved in the process of histone deacetylation and chromatin remodelling (Zhang et al. 1997, Bowen et al. 2004). RBAP46 mRNA expression was reported to be rapidly induced by oestrogens in MCF7 cells (Frasor et al. 2003). Results of previous in vitro studies demonstrated that RBAP46 modulated oestrogen responsiveness in MCF7 cells in a gene-specific manner through interaction with $\mathrm{ER} \alpha$ (Creekmore et al. 2008), and RBAP46 was also reported to inhibit an oestrogen-stimulated progression of transformed breast epithelial cells (Zhang et al. 2007). However, immunohistochemical evaluation of RBAP46 has not been reported in breast carcinoma to the best of our knowledge. In this study, RBAP46 immunoreactivity was more frequently detected in ER-positive pDCIS than in IDC, which also indicated that RBAP46 may play an important role in the alteration of oestrogen actions in the process of transition from pDCIS to IDC.

Survivin is known as an inhibitor of apoptosis, which prevents cell death by mainly blocking activated caspases (Ryan et al. 2006). Survivin mRNA expression was reported to be slowly induced by oestrogen in MCF7 cells (Frasor et al. 2003). Immunolocalisation of cytoplasmic survivin has been reported in human breast carcinoma by several groups, with positivity ranging from 56 to $76 \%$ of pDCIS cases (Barnes et al. 2006, Okumura et al. 2008) and 17 to

Table 6 Association between survivin immunoreactivity and clinicopathological parameters in pDCIS

\begin{tabular}{|c|c|c|c|}
\hline \multirow[b]{2}{*}{ Parameter } & \multicolumn{2}{|c|}{$\begin{array}{c}\text { Survivin } \\
\text { immunoreactivity }\end{array}$} & \multirow[b]{2}{*}{$P$ value } \\
\hline & $\begin{array}{l}\text { High } \\
(n=25)\end{array}$ & $\begin{array}{c}\text { Low } \\
(n=28)\end{array}$ & \\
\hline \multicolumn{4}{|l|}{ Menopausal status $^{a}$} \\
\hline $\begin{array}{l}\text { Premenopausal } \\
\text { Postmenopausal }\end{array}$ & $\begin{array}{r}4(16 \%) \\
21(84 \%)\end{array}$ & $\begin{array}{r}6(21 \%) \\
22(79 \%)\end{array}$ & 0.61 \\
\hline \multicolumn{4}{|l|}{ Nuclear grade $^{a}$} \\
\hline $\begin{array}{l}\text { Grades } 1+2 \\
\text { Grade } 3\end{array}$ & $\begin{array}{r}19(76 \%) \\
6(24 \%)\end{array}$ & $\begin{array}{r}25(89 \%) \\
3(11 \%)\end{array}$ & 0.20 \\
\hline \multicolumn{4}{|l|}{ Comedo necrosis $^{a}$} \\
\hline $\begin{array}{l}\text { Absent } \\
\text { Present }\end{array}$ & $\begin{array}{r}7(28 \%) \\
18(72 \%)\end{array}$ & $\begin{array}{l}11(39 \%) \\
17(61 \%)\end{array}$ & 0.39 \\
\hline ER LI (\%) & $87(27-100)$ & $80(12-100)$ & 0.25 \\
\hline $\begin{array}{l}\text { PR LI (\%) } \\
\text { HER2 status }\end{array}$ & $47(0-100)$ & $40(7-100)$ & 0.58 \\
\hline Negative & $12(48 \%)$ & $17(61 \%)$ & 0.35 \\
\hline Positive & $13(52 \%)$ & $11(39 \%)$ & \\
\hline Ki67 LI (\%) & $4(1-12)$ & $4(1-12)$ & 0.80 \\
\hline
\end{tabular}

Fifty-three pDCIS cases were classified into two (i.e. high and low) groups according to the median value of survivin immunoreactivity. $P$ value $<0.05$ was considered significant and is in boldface. ${ }^{a}$ Data are presented as the number of cases and percentage. All other values represent the median (min-max). 
Table 7 Association of clinicopathological parameters and three oestrogen-induced proteins between DCIS-C and IDC-C in 27 IDC patients

\begin{tabular}{lccc}
\hline Parameter & DCIS-c & IDC-c & $P$ value \\
\hline Nuclear grade $^{\text {a }}$ & & & \\
$\quad$ Grades 1+2 $^{2}$ & $24(33 \%)$ & $24(25 \%)$ & 0.99 \\
$\quad$ rrade 3 & $3(17 \%)$ & $3(17 \%)$ & \\
ER LI (\%) & $80(15-100)$ & $80(8-100)$ & 0.97 \\
PR LI (\%) & $40(0-100)$ & $40(0-100)$ & 0.56 \\
HER2 status a & & & \\
Negative & $18(67 \%)$ & $19(70 \%)$ & 0.77 \\
Positive & $9(33 \%)$ & $8(30 \%)$ & \\
Ki67 LI (\%) & $8(1-23)$ & $12(1-32)$ & 0.04 \\
C-MYB immunoreactivity & $5(0-70)$ & $3(0-70)$ & 0.13 \\
RBAP46 immunoreactivity & $69(0-250)$ & $60(0-230)$ & 0.80 \\
Survivin immunoreactivity & $100(0-220)$ & $80(0-150)$ & 0.19 \\
\hline
\end{tabular}

${ }^{a}$ Data are presented as the number of cases and percentage. All other values represent the median (min-max). $P$ value $<0.05$ was considered significant and is in boldface.

$71 \%$ of IDC cases (Tanaka et al. 2000, Kennedy et al. 2003, Barnes et al. 2006, Sohn et al. 2006, Al-Joudi et al. 2007, Hinnis et al. 2007, Kleinberg et al. 2007). In particular, Barnes et al. (2006) reported that cytoplasmic survivin immunoreactivity was significantly $(P=0.0001)$ frequent in pDCIS compared with IDC, which is consistent with results of this study. In addition, Barnes et al. also reported that the status of survivin immunoreactivity was significantly correlated with pDCIS recurrence and suggested that survivin was involved particularly in an early event of breast carcinoma development. Therefore, anti-apoptotic effects of oestrogen may play an important role also in pDCIS. Results of our present study also demonstrated a positive association between the status of survivin immunoreactivity and patients' age in pDCIS cases (Table 6). Considering a previous report that polymorphisms in survivin promotor were associated with the age of onset of ovarian cancer (Han et al. 2009), some factors other than oestrogen may be involved in the development of pDCIS, but it awaits further investigations for clarification.

Amari et al. (1999) examined the loss of heterozygosity in tumours derived from 23 patients, which harboured synchronous lesions of atypical ductal hyperplasia (ADH), DCIS and IDC, and reported that genetic alterations accumulate during cancer progression from ADH to DCIS and finally to IDC (Amari et al. 1999). However, several groups reported a close association of molecular features between DCIS-c and IDC-c (Done et al. 1998, Half et al. 2002, van der Groep et al. 2009, Burkhardt et al. 2010). In this study, various clinicopathological features and three oestrogen-induced proteins examined were not significantly different between DCIS-c and IDC-c in ER-positive IDC cases. Therefore, alterations of oestrogenic actions may mainly occur at the possible transition from pDCIS to IDC, rather than the intraductal to invasive growth of cancerous cells. Further examinations are required to clarify molecular features of oestrogen actions in pDCIS, which may also contribute to improved histopathological diagnosis of pDCIS through definitive differentiation from DCIS-c of IDC in the biopsy specimen of human breast.

In summary, we examined the expression profiles of oestrogen-induced genes in pDCIS using microarray analysis to characterise molecular features of oestrogen actions in pDCIS. Results demonstrated that one-third of the genes examined were predominantly expressed in pDCIS rather than DCIS-c or IDC-c of IDC cases. Among these pDCIS-associated genes, $C$ - $M Y B$, $R B A P 46$ and survivin immunoreactivity was significantly higher in pDCIS than that in DCIS-c or IDC-c by subsequent immunohistochemical analysis. In particular, C-MYB immunoreactivity was inversely associated with Ki67 LI in pDCIS cases. These results suggest that expression profiles of oestrogen-induced genes in pDCIS are different from those in IDC, and C-MYB, RBAP46 and survivin may play important roles to characterise the oestrogen actions in pDCIS.

\section{Supplementary data}

This is linked to the online version of the paper at http://dx. doi.org/10.1530/ERC-11-0345.

\section{Declaration of interest}

The authors declare that there is no conflict of interest that could be perceived as prejudicing the impartiality of the research reported.

\section{Funding}

This work was partly supported by grant-in-aid for scientific research (22590305) from the Japanese Ministry of Education, Culture, Sports, Science and Technology.

\section{Acknowledgements}

The authors appreciate the skillful technical assistance of $\mathrm{Mr}$ Katsuhiko Ono (Department of Anatomic Pathology, Tohoku University Graduate School of Medicine respectively) despite enormous and unprecedented damages inflicted upon the glass slides, instruments such as tissue processors and others by 3/11 earthquakes in Sendai or Tohoku regions. 


\section{References}

Al-Joudi FS, Iskandar ZA, Hasnan J, Rusli J, Kamal Y, Imran AK, Ahmed M \& Zakaria J 2007 Expression of survivin and its clinicopathological correlations in invasive ductal carcinoma of the breast. Singapore Medical Journal 48 607-614.

Amari M, Suzuki A, Moriya T, Yoshinaga K, Amano G, Sasano H, Ohuchi N, Satomi S \& Horii A 1999 LOH analyses of premalignant and malignant lesions of human breast: frequent $\mathrm{LOH}$ in $8 \mathrm{p}, 16 \mathrm{q}$, and $17 \mathrm{q}$ in atypical ductal hyperplasia. Oncology Reports 6 1277-1280.

de Azambuja E, Cardoso F, de Castro G Jr, Colozza M, Mano MS, Durbecq V, Sotiriou C, Larsimont D, Piccart-Gebhart MJ \& Paesmans M $2007 \mathrm{Ki}-67$ as prognostic marker in early breast cancer: a meta-analysis of published studies involving 12,155 patients. British Journal of Cancer 96 1504-1513. (doi:10.1038/sj.bjc.6603756)

Barnes N, Haywood P, Flint P, Knox WF \& Bundred NJ 2006 Survivin expression in in situ and invasive breast cancer relates to COX-2 expression and DCIS recurrence. British Journal of Cancer 94 253-258. (doi:10.1038/sj.bjc. 6602932)

Bodian CA, Perzin KH, Lattes R \& Hoffmann P 1993

Reproducibility and validity of pathologic classifications of benign breast disease and implications for clinical applications. Cancer 71 3908-3913. (doi:10.1002/10970142(19930615)71:12<3908::AID-CNCR2820711 $218>3.0 . \mathrm{CO} ; 2-\mathrm{F})$

Bowen NJ, Fujita N, Kajita M \& Wade PA 2004 Mi-2/NuRD: multiple complexes for many purposes. Biochimica et Biophysica Acta 1677 52-57.

Burkhardt L, Grob TJ, Hermann I, Burandt E, Choschzick M, Janicke F, Muller V, Bokemeyer C, Simon R, Sauter G et al. 2010 Gene amplification in ductal carcinoma in situ of the breast. Breast Cancer Research and Treatment 123 757-765. (doi:10.1007/s10549-009-0675-8)

Carter CL, Corle DK, Micozzi MS, Schatzkin A \& Taylor PR 1988 A prospective study of the development of breast cancer in 16,692 women with benign breast disease. American Journal of Epidemiology 128 467-477.

Chen Y \& Olopade OI 2008 MYC in breast tumor progression. Expert Review of Anticancer Therapy $\mathbf{8}$ 1689-1698. (doi:10.1586/14737140.8.10.1689)

Chen YY, DeVries S, Anderson J, Lessing J, Swain R, Chin K, Shim V, Esserman LJ, Waldman FM \& Hwang ES 2009 Pathologic and biologic response to preoperative endocrine therapy in patients with ER-positive ductal carcinoma in situ. BMC Cancer 9 285. (doi:10.1186/ 1471-2407-9-285)

Creekmore AL, Walt KA, Schultz-Norton JR, Ziegler YS, McLeod IX, Yates JR \& Nardulli AM 2008 The role of retinoblastoma-associated proteins 46 and 48 in estrogen receptor alpha mediated gene expression. Molecular and Cellular Endocrinology 291 79-86. (doi:10.1016/j.mce. 2008.05.016)
Cuzick J 2003 Treatment of DCIS - results from clinical trials. Surgical Oncology 12 213-219. (doi:10.1016/j. suronc.2003.09.001)

Deisenroth C, Thorner AR, Enomoto T, Perou CM \& Zhang Y 2010 Mitochondrial Hep27 is a c-Myb target gene that inhibits Mdm2 and stabilizes p53. Molecular and Cellular Biology 30 3981-3993. (doi:10.1128/MCB. 01284-09)

van Diest PJ, van der Wall E \& Baak JP 2004 Prognostic value of proliferation in invasive breast cancer: a review. Journal of Clinical Pathology 57 675-681. (doi:10.1136/ jcp.2003.010777)

Done SJ, Arneson NC, Ozcelik H, Redston M \& Andrulis IL 1998 p53 mutations in mammary ductal carcinoma in situ but not in epithelial hyperplasias. Cancer Research $\mathbf{5 8}$ 785-789.

Drabsch Y, Hugo H, Zhang R, Dowhan DH, Miao YR, Gewirtz AM, Barry SC, Ramsay RG \& Gonda TJ 2007 Mechanism of and requirement for estrogen-regulated MYB expression in estrogen-receptor-positive breast cancer cells. PNAS 104 13762-13767. (doi:10.1073/pnas. 0700104104)

Ellis IO, Cornelisse CJ, Schnitt SJ, Sasco AJ, Sastre-Garau X, Kaaks R, Bussolati G, Pisani P, Tavassoli FA, et al. 2003 Invasive breast carcinoma. In World Health Organization Classification of Tumors. Pathology and Genetics of Tumours of the Breast and Female Genital Organs, pp 13-59. Eds FA Tavassoli \& P Devilee. Lyon, France: IARC Press.

Frasor J, Danes JM, Komm B, Chang KC, Lyttle CR \& Katzenellenbogen BS 2003 Profiling of estrogen up- and down-regulated gene expression in human breast cancer cells: insights into gene networks and pathways underlying estrogenic control of proliferation and cell phenotype. Endocrinology 144 4562-4574. (doi:10.1210/en. 2003-0567)

Gerdes J, Schwab U, Lemke H \& Stein H 1983 Production of a mouse monoclonal antibody reactive with a human nuclear antigen associated with cell proliferation. International Journal of Cancer 31 13-20. (doi:10.1002/ijc. 2910310104)

van der Groep P, van Diest PJ, Menko FH, Bart J, de Vries EG \& van der Wall E 2009 Molecular profile of ductal carcinoma in situ of the breast in BRCA1 and BRCA2 germline mutation carriers. Journal of Clinical Pathology 62 926-930. (doi:10.1136/jcp.2009.065524)

Guan LS, Rauchman M \& Wang ZY 1998 Induction of Rb-associated protein (RbAp46) by Wilms' tumor suppressor WT1 mediates growth inhibition. Journal of Biological Chemistry 273 27047-27050. (doi:10.1074/ jbc.273.42.27047)

Guerin M, Sheng ZM, Andrieu N \& Riou G 1990 Strong association between c-myb and oestrogen-receptor expression in human breast cancer. Oncogene 5 131-135.

Half E, Tang XM, Gwyn K, Sahin A, Wathen K \& Sinicrope FA 2002 Cyclooxygenase-2 expression in human breast cancers and adjacent ductal carcinoma in situ. Cancer Research 62 1676-1681. 
Hammond ME, Hayes DF, Dowsett M, Allred DC, Hagerty KL, Badve S, Fitzgibbons PL, Francis G, Goldstein NS, Hayes M et al. 2010 American Society of Clinical Oncology/College Of American Pathologists guideline recommendations for immunohistochemical testing of estrogen and progesterone receptors in breast cancer. Journal of Clinical Oncology 28 2784-2795.

(doi:10.1200/JCO.2009.25.6529)

Han CH, Wei Q, Lu KK, Liu Z, Mills GB \& Wang LE 2009 Polymorphisms in the survivin promoter are associated with age of onset of ovarian cancer. International Journal of Clinical and Experimental Medicine 2 289-299.

Hinnis AR, Luckett JC \& Walker RA 2007 Survivin is an independent predictor of short-term survival in poor prognostic breast cancer patients. British Journal of Cancer 96 639-645. (doi:10.1038/sj.bjc.6603616)

Hwang ES, DeVries S, Chew KL, Moore DH II, Kerlikowske K, Thor A, Ljung BM \& Waldman FM 2004 Patterns of chromosomal alterations in breast ductal carcinoma in situ. Clinical Cancer Research 10 5160-5167. (doi:10.1158/1078-0432.CCR-04-0165)

Irvine T \& Fentiman IS 2007 Biology and treatment of ductal carcinoma in situ. Expert Review of Anticancer Therapy 7 135-145. (doi:10.1586/14737140.7.2.135)

Kennedy SM, O’Driscoll L, Purcell R, Fitz-Simons N, McDermott EW, Hill AD, O’Higgins NJ, Parkinson M, Linehan R \& Clynes M 2003 Prognostic importance of survivin in breast cancer. British Journal of Cancer $\mathbf{8 8}$ 1077-1083. (doi:10.1038/sj.bjc.6600776)

Kepple J, Henry-Tillman RS, Klimberg VS, Layeeque R, Siegel E, Westbrook K \& Korourian S 2006 The receptor expression pattern in ductal carcinoma in situ predicts recurrence. American Journal of Surgery 192 68-71. (doi:10.1016/j.amjsurg.2006.04.002)

Klebig C, Korinth D \& Meraldi P 2009 Bub1 regulates chromosome segregation in a kinetochore-independent manner. Journal of Cell Biology 185 841-858. (doi:10.1083/jcb.200902128)

Kleinberg L, Florenes VA, Nesland JM \& Davidson B 2007 Survivin, a member of the inhibitors of apoptosis family, is down-regulated in breast carcinoma effusions. American Journal of Clinical Pathology 128 389-397. (doi:10.1309/E899BG1282M5D505)

Lakhani SR, Chaggar R, Davies S, Jones C, Collins N, Odel C, Stratton MR \& O’Hare MJ 1999 Genetic alterations in 'normal' luminal and myoepithelial cells of the breast. Journal of Pathology 189 496-503. (doi:10.1002/ (SICI)1096-9896(199912)189:4 < 496::AID-PATH485> 3.0.CO;2-D)

Li CI, Daling JR \& Malone KE 2005 Age-specific incidence rates of in situ breast carcinomas by histologic type, 1980 to 2001. Cancer Epidemiology Biomarkers \& Prevention 14 1008-1011. (doi:10.1158/1055-9965.EPI-04-0849)

McCarty KS Jr, Miller LS, Cox EB, Konrath J \& McCarty KS Sr 1985 Estrogen receptor analyses. Correlation of biochemical and immunohistochemical methods using monoclonal antireceptor antibodies. Archives of Pathology \& Laboratory Medicine 109 716-721.

McHale K, Tomaszewski JE, Puthiyaveettil R, Livolsi VA \& Clevenger CV 2008 Altered expression of prolactin receptor-associated signaling proteins in human breast carcinoma. Modern Pathology 21 565-571.

Mehta RJ, Jain RK, Leung S, Choo J, Nielsen T, Huntsman D, Nakshatri H \& Badve S 2012 FOXA1 is an independent prognostic marker for ER-positive breast cancer. Breast Cancer Research and Treatment 131 881-890. (doi:10.1007/s10549-011-1482-6)

Nofech-Mozes S, Spayne J, Rakovitch E \& Hanna W 2005 Prognostic and predictive molecular markers in DCIS: a review. Advances in Anatomic Pathology 12 256-264. (doi:10.1097/01.pap.0000184177.65919.5e)

Oh IH \& Reddy EP 1999 The myb gene family in cell growth, differentiation and apoptosis. Oncogene 18 3017-3033. (doi:10.1038/sj.onc.1202839)

Okumura Y, Yamamoto Y, Zhang Z, Toyama T, Kawasoe T, Ibusuki M, Honda Y, Iyama K, Yamashita H \& Iwase H 2008 Identification of biomarkers in ductal carcinoma in situ of the breast with microinvasion. BMC Cancer 8 287. (doi:10.1186/1471-2407-8-287)

Park K, Han S, Kim HJ, Kim J \& Shin E 2006 HER2 status in pure ductal carcinoma in situ and in the intraductal and invasive components of invasive ductal carcinoma determined by fluorescence in situ hybridisation and immunohistochemistry. Histopathology 48 702-707. (doi:10.1111/j.1365-2559.2006.02403.x)

Robanus-Maandag EC, Bosch CA, Kristel PM, Hart AA, Faneyte IF, Nederlof PM, Peterse JL \& van de Vijver MJ 2003 Association of C-MYC amplification with progression from the in situ to the invasive stage in C-MYCamplified breast carcinomas. Journal of Pathology 201 75-82. (doi:10.1002/path.1385)

Ryan BM, Konecny GE, Kahlert S, Wang HJ, Untch M, Meng G, Pegram MD, Podratz KC, Crown J, Slamon DJ et al. 2006 Survivin expression in breast cancer predicts clinical outcome and is associated with HER2, VEGF, urokinase plasminogen activator and PAI-1. Annals of Oncology 17 597-604. (doi:10.1093/annonc/mdj121)

Shibuya R, Suzuki T, Miki Y, Yoshida K, Moriya T, Ono K, Akahira J, Ishida T, Hirakawa H, Evans DB et al. 2008 Intratumoral concentration of sex steroids and expression of sex steroid-producing enzymes in ductal carcinoma in situ of human breast. Endocrine-Related Cancer 15 113-124. (doi:10.1677/ERC-07-0092)

Sohn DM, Kim SY, Baek MJ, Lim CW, Lee MH, Cho MS \& Kim TY 2006 Expression of survivin and clinical correlation in patients with breast cancer. Biomedicine \& Pharmacotherapy 60 289-292. (doi:10.1016/j.biopha. 2006.06.008)

Sontag L \& Axelrod DE 2005 Evaluation of pathways for progression of heterogeneous breast tumors. Journal of Theoretical Biology 232 179-189. (doi:10.1016/j.jtbi. 2004.08.002) 
Suzuki T, Inoue A, Miki Y, Moriya T, Akahira J, Ishida T, Hirakawa H, Yamaguchi Y, Hayashi S \& Sasano H 2007 Early growth responsive gene 3 in human breast carcinoma: a regulator of estrogen-meditated invasion and a potent prognostic factor. Endocrine-Related Cancer 14 279-292. (doi:10.1677/ERC-06-0005)

Suzuki S, Takagi K, Miki Y, Onodera Y, Akahira JI, Ebata A, Ishida T, Watanabe M, Sasano H \& Suzuki T 2012 Nucleobindin 2 (NUCB2) in human breast carcinoma as a potent prognostic factor. Cancer Science 103 136-143. (doi:10.1111/j.1349-7006.2011.02119.x)

Tanaka K, Iwamoto S, Gon G, Nohara T, Iwamoto M \& Tanigawa N 2000 Expression of survivin and its relationship to loss of apoptosis in breast carcinomas. Clinical Cancer Research 6 127-134.

Thorner AR, Parker JS, Hoadley KA \& Perou CM 2010 Potential tumor suppressor role for the c-Myb oncogene in luminal breast cancer. PLOS ONE 5 e13073. (doi:10.1371/ journal.pone.0013073)

Tsikitis VL \& Chung MA 2006 Biology of ductal carcinoma in situ classification based on biologic potential. American Journal of Clinical Oncology 29 305-310. (doi:10.1097/ 01.coc.0000198740.33617.2f)

Wiechmann L \& Kuerer HM 2008 The molecular journey from ductal carcinoma in situ to invasive breast cancer. Cancer 112 2130-2142. (doi:10.1002/cncr.23430)

Wolff AC, Hammond ME, Schwartz JN, Hagerty KL, Allred DC, Cote RJ, Dowsett M, Fitzgibbons PL, Hanna WM, Langer A et al. 2007 American Society of Clinical
Oncology/College of American Pathologists guideline recommendations for human epidermal growth factor receptor 2 testing in breast cancer. Journal of Clinical Oncology 25 118-145. (doi:10.1200/JCO.2006. 09.2775)

Xu Y, Fang F, Ludewig G, Jones G \& Jones D 2004 A mutation found in the promoter region of the human survivin gene is correlated to overexpression of survivin in cancer cells. DNA and Cell Biology 23 527-537.

Zhang Y, Iratni R, Erdjument-Bromage H, Tempst P \& Reinberg D 1997 Histone deacetylases and SAP18, a novel polypeptide, are components of a human Sin3 complex. Cell 89 357-364. (doi:10.1016/S00928674(00)80216-0)

Zhang TF, Yu SQ \& Wang ZY 2007 RbAp46 inhibits estrogen-stimulated progression of neoplastigenic breast epithelial cells. Anticancer Research 27 3205-3209.

Zhang J, Luo N, Luo Y, Peng Z, Zhang T \& Li S 2012 microRNA-150 inhibits human CD133-positive liver cancer stem cells through negative regulation of the transcription factor c-Myb. International Journal of Oncology 40 747-756. (doi:10.3892/ijo.2011.1242)

Received in final form 25 April 2012

Accepted 4 May 2012

Made available online as an Accepted Preprint 8 May 2012 